\title{
Temporal Asymmetry in Dark-Bright Processing Initiates Propagating Activity across Primary Visual Cortex
}

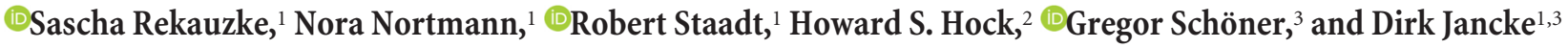 \\ ${ }^{1}$ Optical Imaging Group, Institut für Neuroinformatik, Ruhr University Bochum, 44801 Bochum, Germany, ${ }^{2}$ Department of Psychology, Florida Atlantic \\ University, Boca Raton, Florida 33486, and ${ }^{3}$ Theory of Cognitive Systems, Institut für Neuroinformatik, Ruhr University Bochum, 44801 Bochum, Germany
}

Differences between visual pathways representing darks and lights have been shown to affect spatial resolution and detection timing. Both psychophysical and physiological studies suggest an underlying retinal origin with amplification in primary visual cortex (V1). Here we show that temporal asymmetries in the processing of darks and lights create motion in terms of propagating activity across V1. Exploiting the high spatiotemporal resolution of voltage-sensitive dye imaging, we captured population responses to abrupt local changes of luminance in cat V1. For stimulation we used two neighboring small squares presented on either bright or dark backgrounds. When a single square changed from dark to bright or vice versa, we found coherent population activity emerging at the respective retinal input locations. However, faster rising and decay times were obtained for the bright to dark than the dark to bright changes. When the two squares changed luminance simultaneously in opposite polarities, we detected a propagating wave front of activity that originated at the cortical location representing the darkened square and rapidly expanded toward the region representing the brightened location. Thus, simultaneous input led to sequential activation across cortical retinotopy. Importantly, this effect was independent of the squares' contrast with the background. We suggest imbalance in dark-bright processing as a driving force in the generation of wave-like activity. Such propagation may convey motion signals and influence perception of shape whenever abrupt shifts in visual objects or gaze cause counterchange of luminance at high-contrast borders.

Key words: luminance counterchange; motion encoding; ON/OFF visual pathways; propagating activity; visual cortex; voltage-sensitive dye imaging

\section{Significance Statement}

An elementary process in vision is the detection of darks and lights through the retina via ON and OFF channels. Psychophysical and physiological studies suggest that differences between these channels affect spatial resolution and detection thresholds. Here we show that temporal asymmetries in the processing of darks and lights create motion signals across visual cortex. Using two neighboring squares, which simultaneously counterchanged luminance, we discovered propagating activity that was strictly drawn out from cortical regions representing the darkened location. Thus, a synchronous stimulus event translated into sequential wave-like brain activation. Such propagation may convey motion signals accessible in higher brain areas, whenever abrupt shifts in visual objects or gaze cause counterchange of luminance at high-contrast borders.

\section{Introduction}

A fundamental neuronal operation in vision is the processing of local luminance decrements and increments across $\mathrm{ON}$ and $\mathrm{OFF}$

\footnotetext{
Received Aug. 28, 2015; revised Dec. 3, 2015; accepted Dec. $26,2015$.

Author contributions: S.R., H.S.H., G.S., and D.J. designed research; S.R., N.N., H.S.H., and D.J. performed research; D.J. contributed unpublished reagents/analytic tools; S.R., R.S., and D.J. analyzed data; D.J. wrote the paper.

This work was supported by grants from the Deutsche Forschungsgemeinschaft, SFB-874 (TPA2), German-Israeli Project Cooperation (DIP, JA 945/3-1, SL 185/1-1), SPP 1665 (JA 945/4-1), and the Bundesministerium für Bildung und Forschung, BMBF, Bernstein Group Computational Neuroscience Bochum. We thank Drs Hamutal Slovin and Hubert Dinse for discussion and Stefan Dobers for technical assistance.

The authors declare no competing financial interests.

This article is freely available online through the J Neurosci Author Open Choice option.

Correspondence should be addressed to Dr Dirk Jancke, Optical Imaging Group, Institut für Neuroinformatik,

NB2/27, Ruhr University Bochum, Universitätstr. 150, D-44780 Bochum, Germany. E-mail: dirk.jancke@rub.de.

DOI:10.1523/JNEUROSCI.3235-15.2016
}

pathways. For primary visual cortex (V1), early reports (Bishop et al., 1971) and more recent studies in primates and cats suggest remarkable asymmetries in the pathways' functional properties. That is, OFF responses dominate the representation of area centralis in cat, most likely based on pronounced OFF-center geniculate afferents (Jin et al., 2008). Single-cell activity in layer $2 / 3$ of macaque $\mathrm{V} 1$ is stronger for black stimuli than for white (Yeh et al., 2009), presumably based on recurrent amplification of signals arising from thalamocortical input layers (Yeh et al., 2009; Xing et al., 2010). Moreover, in cat V1, latencies of thalamic afferents in Creative Commons Attribution 4.0 International, which permits unrestricted use, distribution and reproduction in any medium provided that the original work is properly attributed. 
response to stimulus darkening were found to be 3-6 ms shorter than for brightening (Jin et al., 2011a). Further along this line, for rectified flashed gratings it was shown that responses to the dark half dominate spiking responses to the light half (Kremkow et al., 2014), possibly leading to retinotopic cortical propagation of a moving grating's first harmonics as visualized using voltagesensitive dye (VSD) imaging (Onat et al., 2011). The origin of such differential processing may be traced back to the level of photoreceptor kinetics where nonlinearities in the luminanceresponse function of the retina (Chichilnisky and Kalmar, 2002; Zaghloul et al., 2003) may ultimately lead to increased strength of V1 responses for darks over lights (Komban et al., 2014; Kremkow et al., 2014), in particular at low spatial frequencies (Zemon et al., 1988; Onat et al., 2011; Kremkow et al., 2014). Hence, it seems clear that processing of local stimulus darkening dominates brightening in these species (as opposed to rodents; Polack and Contreras, 2012) up to the level of V1 and may reflect nonuniformities in the distribution of bright and dark components in natural images (Cooper and Norcia, 2015).

Here we address the question of how the observed asymmetries in dark-bright processing affect local cortical activation dynamics. We used VSD imaging that provides spatiotemporal resolution of population activity at a mesoscopic scale (Freeman and Barrie, 2000; Dinse and Jancke, 2001), with emphasis on superficial cortical layers (Grinvald et al., 1994; Petersen et al., 2003; Grinvald and Hildesheim, 2004; Jancke et al., 2004a; Roland et al., 2006; Onat et al., 2011). Recent VSD imaging in monkey V1, using square stimuli that were larger than receptive fields, showed pronounced differences between the retinotopic representation of darks and lights (Zurawel et al., 2014). These differences were particularly strong at the representations of surface centers and corners of the stimuli (Zurawel et al., 2014). In the present study, we used VSD imaging in the cat to explore the characteristics of V1 population activity in response to darkening and brightening of small squares with sizes in the range of receptive fields.

We found coherent and retinotopically organized cortical patterns in which population activity for local stimulus darkening was significantly enhanced during the rise time of the responses, followed by earlier decay compared with stimulus brightening. Additionally, a setting was used in which the luminance of two squares at neighboring positions changed simultaneously in opposite directions. Interestingly, in humans such stimuli evoke motion perception that is most vivid when the delay between the squares' luminance changes is zero (Hock et al., 2002). We discovered that simultaneous counterchange in local luminance produced asymmetric wave-like propagation of activity across V1. Population activity started from the cortical location representing the square that darkened and was drawn out toward cortical locations representing the square that brightened. Thus, a single simultaneous stimulus switch led to sequential activation across cortical retinotopy. The results suggest that dark over bright spatiotemporal asymmetries provide a driving force for this effect. The observed propagation may play a role in the generation of V1 motion signals following counterchange of luminance at high-contrast borders of shifting objects and may influence their perceived shape.

\section{Materials and Methods}

Preparations for optical imaging

All experiments were performed in accordance with the European Union Community Council guidelines and approved by the German Animal Care and Use Committee (application number: AZ 9.93.2.10.32.07.032) in accordance with the Deutsches Tierschutzgesetz ( $\$ 8$ Abs. 1 ) and the
$\mathrm{NIH}$ guidelines. Cats ( 5 male and 6 female, adult) were initially anesthetized with ketamine $\left(20 \mathrm{mg} \cdot \mathrm{kg}^{-1}, \mathrm{i} . \mathrm{m}\right.$. $)$ and xylazine $\left(1 \mathrm{mg} \cdot \mathrm{kg}^{-1}, \mathrm{i} . \mathrm{m}\right.$. $)$, artificially respirated (Ugo Basile), continuously anesthetized with 0.8 $1.5 \%$ isoflurane in a $1: 1$ mixture of $\mathrm{O}_{2} / \mathrm{N}_{2} \mathrm{O}$, and fed intravenously. Following surgery paralysis was induced and maintained by Alloferin $\left(0.06 \mathrm{mg} \cdot(\mathrm{kg} \cdot \mathrm{h})^{-1}\right.$, i.v.; Valeant Pharmaceuticals) or Pancuronium $\left(0.05 \mathrm{mg} \cdot(\mathrm{kg} \cdot \mathrm{h})^{-1}\right.$, i.v.; Inresa). To control for eye drift, the position of the area centralis and receptive-field positions were measured repeatedly. We administered $0.4 \mathrm{mg} \cdot \mathrm{kg}^{-1}$ Dexamethasone and $0.05 \mathrm{mg} \cdot \mathrm{kg}^{-1}$ atropine sulfate, intramuscularly, daily, and $20 \mathrm{mg} \cdot \mathrm{kg}^{-1}$ Cephazolin, intravenously, twice a day. Zero-power contact lenses with a $3 \mathrm{~mm}$ diameter pupil were used as protectives and lenses were used to focus the eyes on the screen. Heart rate, intratracheal pressure, exhaled $\mathrm{CO}_{2}$, and body temperature were monitored. The skull was opened above area V1, the dura was removed, and a chamber was mounted. The cortex was stained for 2-3 h with VSD (RH-1691) and afterward unbound dye was washed out with artificial CSF (for further details, see Onat et al., 2011; Nortmann et al., 2015).

\section{Visual stimuli and presentation}

Small squares $\left(\right.$ mean size $\left.=1.8^{\circ} \pm 0.47 \mathrm{SD}\right)$ were presented on a monitor (100 Hz, Sony Triniton GDM-FW900). Stimuli were generated by the VSG2/5 system (Cambridge Research Systems) running on custom scripts written for MATLAB 6.5 (MathWorks). To produce highcontrast changes without inversion of contrast polarity, stimuli were displayed on dark $\left(2 \mathrm{~cd} / \mathrm{m}^{2}\right)$ or bright background $\left(110 \mathrm{~cd} / \mathrm{m}^{2}\right)$ and were turned bright (from 15 to $95 \mathrm{~cd} / \mathrm{m}^{2}$ ) or dark (from 95 to $15 \mathrm{~cd} / \mathrm{m}^{2}$ ). A blank condition comprised recordings during which the backgrounds were presented without luminance change to allow correction of breathing and heartbeat artifacts. We measured responses to single square luminance changes and simultaneous changes of luminance of two neighboring squares (mean center-to-center distance $=7.5^{\circ} \pm 1.7 \mathrm{SD}$ ).

Stimulus presentation took place over two frames. The squares were presented against their background during the first frame. Luminance was changed at the outset of the second frame during which optical data were recorded for $1 \mathrm{~s}$ per trial, including a $200 \mathrm{~ms}$ prestimulus baseline. The intertrial interval was set to a minimum of $5 \mathrm{~s}$. Stimulus conditions were randomized across trials.

For calibration and mapping of orientation preference, we used moving square-wave gratings (rms-contrast: $1,0.2 \mathrm{c} /{ }^{\circ}, 6 \mathrm{~Hz}$, mean luminance $\left.53 \mathrm{~cd} / \mathrm{m}^{2}\right)$ with two different orientations $\left(0^{\circ}, 90^{\circ}\right)$.

\section{Data acquisition and preprocessing}

Optical imaging. Optical imaging was conducted with Imager 3001 (Optical Imaging). The camera (frames of $512 \times 512$ pixels, 1 pixel $=107$ $\mu \mathrm{m}$ ) was focused $\sim 400-500 \mu \mathrm{m}$ below the cortical surface. Data acquisition onset was synchronized with heartbeat and respiration. For detection of changes in fluorescence, the cortex was illuminated with light of wavelength $630 \pm 10 \mathrm{~nm}$, and emitted light at wavelengths $>665 \mathrm{~nm}$ was collected. The camera frame rate was set to $100 \mathrm{~Hz}$. We performed normalization by dividing each pixel value by its average $70 \mathrm{~ms}$ prestimulus activity; heartbeat and respiration related artifacts were removed by subtracting the average blank signal (2 blanks were recorded per stimulus trial). These preprocessing steps lead to a unitless relative signal of fluorescence, denoted by $\Delta \mathrm{F} / \mathrm{F}$. For analysis, images were smoothed using a two-dimensional Gaussian filter ( $\sigma=15$ pixels). Z-scores were computed by dividing each pixel (unfiltered data, mean-free) by its SD calculated over the entire time course during blank conditions.

Electrophysiology. Multiunit activity was collected at a depth between 400 and $600 \mu \mathrm{m}$. Before electrophysiology, a vascular map of the brain was captured by illumination with green light $(546 \mathrm{~nm})$ from two optic fiber light guides. Spikes were sorted online by a multiple spike detector (Alpha Omega Engineering) or using the spike2 software (Cambridge Electronic Design). Multiunit activity (mostly 3-4 cells) was recorded with tungsten electrodes $(0.8-1.2 \mathrm{M} \Omega$, WPI). Data were averaged over $5 \mathrm{~ms}$ bins and temporally filtered using a sliding Gaussian window $(\sigma=3$ bins $)$. 

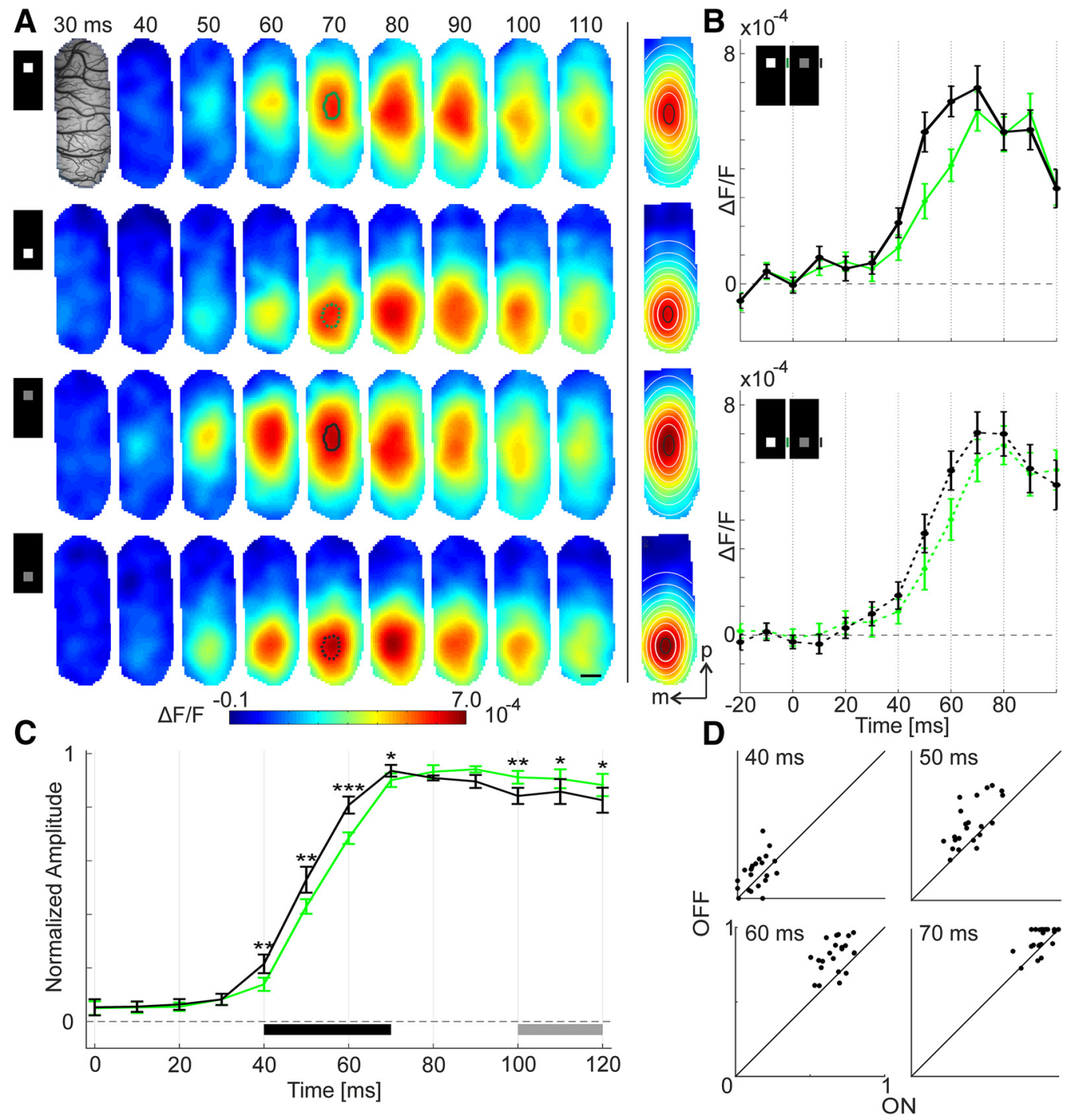

Figure 1. Local stimulus brightening and darkening cause temporal differences in processing across V1. A, Population activity captured with VSD imaging. Image frames show responses to squares $\left(1.5^{\circ}\right)$ at two different visual field positions (see icons at left), time after stimulus onset depicted at top. Top, left, frame shows vascular pattern of the imaged cortex. Squares were presented on a dark $\left(2 \mathrm{~cd} / \mathrm{m}^{2}\right)$ background and turned either bright (two top rows) or dark (two bottom rows). Amplitudes of activity (average over 24 repetitions) are expressed as relative changes in fluorescence, $\Delta F / F$, color bar at bottom. Black line $=1 \mathrm{~mm}$. p, Posterior; $\mathrm{m}$, medial. Frames at right column show temporal averages ( $50-80 \mathrm{~ms}$ ) overlaid with $2 D \mathrm{Gaussian}$ fits. $B$, Time courses of responses to darkened squares (black) and brightened squares (green) as spatial averages across encircled regions shown in $A$. Error bars $=S D$ over pixels. $C$, Average of time courses across all experiments $(N=11)$ and both square positions. Traces depict mean. Error bars $=\mathrm{SEM}$. Color scheme as in $\boldsymbol{B}$. Bars at bottom mark time segments with $p=0.0088$ (black) and $p=0.0410$ (gray) after run-length-corrected permutation tests (see Materials and Methods). For reference the uncorrected sample-by-sample $p$ values are marked, ${ }^{*} p<0.05,{ }^{* *} p<0.01$, ${ }^{* * *} p<0.001$ (two-sided $t$ test). $\boldsymbol{D}$, Normalized amplitudes for darkened squares (OFF) versus brightened squares (ON) for each single experiment and time step.

\section{Permutation tests}

To account for the problem of multiple comparisons when assessing the differences between time traces of two conditions at various time points (Fig. 1C) we used a permutation test (Blair and Karniski, 1993). This procedure enables localization of time segments at which the differences between the two conditions have $p$ values $<0.05$ (Appelbaum et al., 2006, 2012). In a first step, the time traces for two conditions (ie, square darkening and square brightening) were systematically permuted across experiments, covering all possible permutations. For each permutation and at each point in time the significance values for differences between conditions were calculated using a two-sided $t$ test. In a second step, the cumulative distribution of $t$ scores obtained from the permuted traces was used to determine the threshold length of consecutive time points with significant $t$ scores that exceeded $95 \%$ of such lengths expected by chance. The conditions were considered different when the longest run of significant $t$ scores in the original data exceeded this threshold length. When the test confirmed a difference between conditions, we marked time segments with $p<0.05$ in the original traces (Fig. $1 C$; for detailed mathematical description, see Appelbaum et al., 2006).

\section{Human psychophysics}

Experiments were performed in accord with the protocols of the Internal Review Board at Florida Atlantic University. Three participants (2 male, 1 female, with normal or corrected-to-normal vision) were tested. Two different sizes and distances of the squares were used (square size of $1.8^{\circ}$ with $7.5^{\circ}$ center-to-center distance, in accord with the mean size and the mean distance applied across all cat experiments, and square size of $1.5^{\circ}$ with $5.25^{\circ}$ center-to-center distance for the cat experiment shown in Fig. 3 ). Luminance values of the background and the squares were identical to the cat experiments. Two neighboring squares were presented on dark background. Each trial started with either the upper square being bright and the lower square gray or vice versa, followed by synchronous counterchange of luminance at the two locations. Blocks of 40 trials were determined by the orthogonal combination of both directions of the 
luminance changes. In one block of trials subjects indicated whether or not they perceived motion, and if so, its direction. In a second block of trials subjects indicated whether or not they perceived motion, and if so, whether it was the lighter or darker square that appeared to be moving.

\section{Results}

We used VSD imaging in cat V1 to capture the joint spatiotemporal population dynamics in response to local stimuli which underwent a sudden change in luminance. Gray squares, presented on uniform dark or white backgrounds, turned either ON to bright or were switched OFF, back to gray, thus switching luminance with equal decrements or increments while leaving the contrast change the same for both. The evoked activity patterns were recorded across $\sim 5 \times 10 \mathrm{~mm}$ patches of cortex.

\section{Darkening and brightening of local stimuli induce different population dynamics}

Figure $1 A$, top row, shows $10 \mathrm{~ms}$ image frames of cortical population activity induced by stimulus brightening for a single experiment. Activity emerged coherently at the site of thalamic input and spread rapidly across the imaged cortical area. The spread at lowest amplitudes (bluish colors) reflected most likely postsynaptic subthreshold activation (Bringuier et al., 1999) expanding via horizontal connections (Fisken et al., 1975; Creutzfeldt et al., 1977; Gilbert and Wiesel, 1979; Palagina et al., 2009). Activity reaching high amplitudes indicated direct input, and hence, remained localized with only a little expansion, as demonstrated earlier using VSD imaging of local stimuli in cat visual cortex (Jancke et al., 2004a; Sharon et al., 2007; Chavane et al., 2011; Onat et al., 2013). Presentation of the same stimulus at a lower location in the visual field ( $5^{\circ}$ center-to-center distance) led to overall similar signatures of the response dynamics together with the expected retinotopic shift of activation toward anterior locations (Fig. 1A, second row). Note that because stimulus sizes were identical, activity for the lower square covered a slightly smaller cortical region (Fig. 1A, Gaussian fits of time averages at right column), reflecting increased eccentricity (Albus, 1975). Importantly, when the squares turned dark, ie, turned "OFF" (Fig. 1A, third and fourth rows), we discovered that amplitudes of activity ascended $\sim 10$ ms earlier than for stimulus brightening (Fig. $1 A, B$; compare 40 and $50 \mathrm{~ms}$ frames). The temporal advance of increased amplitudes was preserved throughout the subsequent 30 ms time window, followed by earlier decay of activity compared with conditions where the squares turned bright (ie, "ON"). Figure $1 C$ summarizes these findings across nine different experiments ( $N=11$ hemispheres; black trace represents square darkening, green represents brightening). The graphs depict mean normalized time courses of spatial averages across the $10 \%$ most active pixels within the image frames of each experiment. It can be seen that during the rise time of the responses (40-70 ms) activity for stimulus darkening (black curve) was consistently higher than for stimulus brightening (Fig. $1 C$, bottom horizontal black bar, $p<0.01$ ) as evaluated by run-length corrected permutation tests (Appelbaum et al., 2006, 2012). In contrast, after $\sim 80 \mathrm{~ms}$ activity for the darkened square was reduced compared with the brightened square, suggesting an earlier decay of activity for stimulus darkening than for brightening (Fig. 1C, compare bottom gray bar; $p<0.05$, run-length corrected). Over all experiments the difference in amplitude between darks and lights during 50-60 ms rise time was $19.3 \pm$ 9.2\% SEM (Fig. 1D; illustrates normalized values for each single experiment, both square positions, and for each $10 \mathrm{~ms}$ time step). When the squares were presented on bright background (110 $\mathrm{cd} / \mathrm{m}^{2}$ ) rise-time amplitudes for the darkened squares were further increased $29.3 \pm 14.6 \%$ SEM compared with brightened squares $(N=6$ experiments, data not shown), suggesting background-dependent nonlinearities upon luminance decrements and increments (Kremkow et al., 2014). We additionally found that response profiles for darkening and brightening were equal in size $(\sigma=1.99 \pm 0.1 \mathrm{~mm} \mathrm{SEM}$, values along major axis of the Gaussian fits) except for the square brightening on a dark background $(\sigma=1.70 \pm 0.09 \mathrm{~mm}$ SEM, $p=0.018$, two-sided Wilcoxon signed-rank test). This indicates that a smaller pool of neurons is recruited in the latter condition, potentially leading to less effective gain control (Sit et al., 2009) or reduced lateral suppression (Ferster, 1986; Nelson, 1991; Jancke et al., 1999), which in turn may contribute to the generation of larger receptive fields for lights on dark background than observed for opposite contrasts and brighter backgrounds (Kremkow et al., 2014). Altogether, we show that for an identical amount of change in stimulus luminance, population activity in response to stimulus darkening dominated responses to brightening during response rise times followed by earlier decay (Fig. $1 C$ ). As the effect was similar for bright and dark backgrounds, it is furthermore indicated that the responses were determined by the direction of luminance change rather than the direction of luminance contrast change.

The VSD fluorescent signal reports continuous changes of the average membrane potential across the entire recorded neuronal population. Thus, even though the emergence of spiking population activity is expected to coincide with high VSD signal amplitudes (for such observations in similar experimental conditions, see Jancke et al., 2004a) suprathreshold activation cannot be inferred directly. We therefore provided evidence for the occurrence of spikes using extracellular recordings. In all experiments, the upper square was positioned such that it was covered by the multiunit receptive fields derived at the recording electrode, and in nine different experiments, responses to the whole stimulus set were measured. Figure $2 A$ shows hand-mapped receptive fields ( $N=16$ penetration sites) together with the relative positions of the square stimuli. In accordance with the imaging data, we found earliest spiking activity $\sim 30-40 \mathrm{~ms}$ after stimulus onset (Fig. 2B, two top plots of the poststimulus time histograms). Importantly, similar to the imaged responses, spiking activity for stimulus darkening was significantly increased compared with stimulus brightening during the rise time of the responses (bottom panel in Fig. $2 B$, bottom, depicts differences of normalized data; Bonferroni corrected, one-sided Wilcoxon signed-rank test, $p<0.05$ ), along with a steeper slope ( $96 \%$ of the explainable variance across experiments) for the darkened square compared with its brightening ( $97 \%$ explainable variance). Moreover, as expected, spiking activity occurred at cortical locations that displayed the highest imaging signals (Fig. 5 for individual electrode positions). Thus, our spike recordings confirmed that equal amounts of decrease and increase of local stimulus luminance produce different temporal onset dynamics at suprathreshold levels that are dominated by responses to darkening.

\section{Simultaneous counterchange of luminance at neighboring positions produce propagation of cortical activity}

During scanning of a visual scene or while objects move across the visual field, simultaneous reversals in stimulus luminance naturally occur at different retinal locations that may coincide with high levels of local information content in terms of contrast, entropy, and correlation (McCamy et al., 2014). In particular the 
A

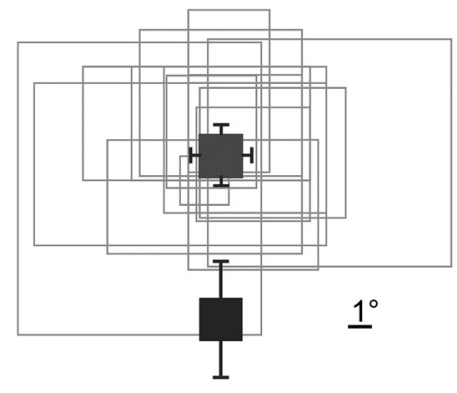

B

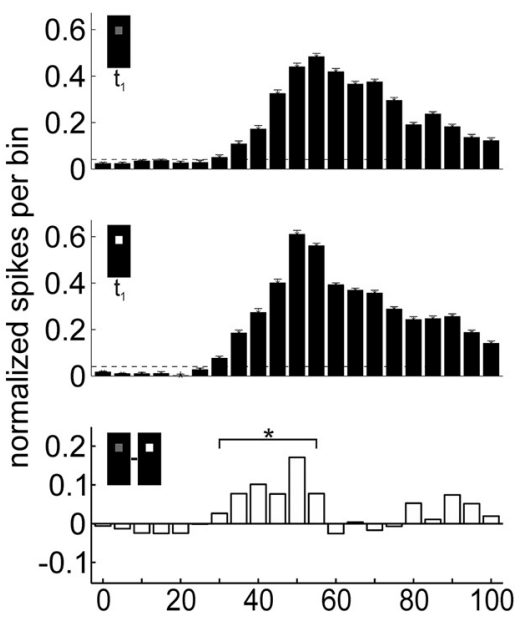

C
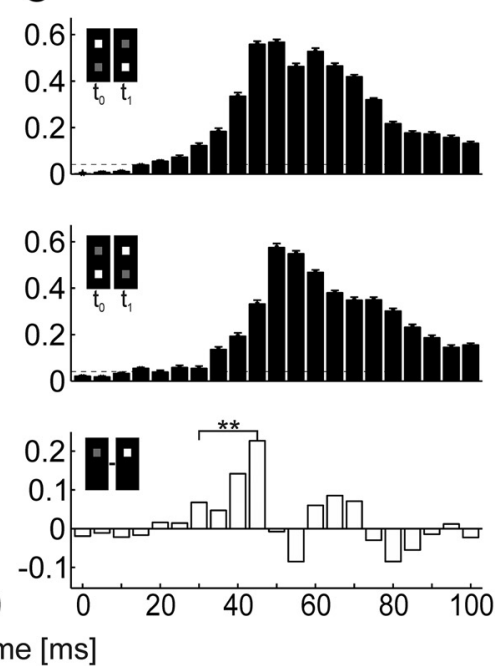

Figure 2. Electrophysiology. $\boldsymbol{A}$, Hand-mapped receptive fields, sizes and relative positions of the used square stimuli. Square sizes varied slightly dependent on eccentricity in the individual experiments (mean distance to projection of area centralis was $8.24^{\circ} \pm 3.6 \mathrm{SD}$, mean stimulus size $1.8^{\circ} \pm 0.47 \mathrm{SD}$, mean center-to-center distance $7.5^{\circ} \pm 1.7 \mathrm{SD}$ ). $\boldsymbol{B}$, Responses to top square darkening (top plot) and brightening (bottom plot), depicted as normalized spike count per bin (16 multiunit recordings, 9 different experiments, error bars $=$ SEM). Bottom, Differences in amplitudes between responses to stimulus darkening and brightening. $\boldsymbol{C}$, Same as $\boldsymbol{B}$ with two squares that counterchange luminance. Stippled horizontal lines mark significant increase ( $p>3$ SD) over spontaneous activity. ${ }^{*} p<0.05,{ }^{* *} p<0.01$, Bonferroni corrected, one-sided Wilcoxon signed-rank test.

sudden onset of motion in natural scenes may produce counterchange of luminance along surfaces or edges, inevitably embedding characteristic regularities such as asymmetries in contrast distributions (Ruderman and Bialek, 1994; Geisler, 2008; Ratliff et al., 2010). For instance, dark-light asymmetries across natural scenes improve perception of object motion using triple correlations across luminance changes (Clark et al., 2014). With the visual system pushed to its limits, predators might exploit counterchanges of luminance for the detection of camouflagebreaking object motion (Yin et al., 2015).

How would the observed V1 population dynamics reflect simultaneous darkening and brightening at adjacent locations? To answer this question, we measured cortical responses after two squares presented at neighboring locations counterchanged luminance at the same time; ie, there was a luminance decrement for one square and a luminance increment at the other. Our electrode recordings revealed that the temporal advance of activity evoked by the darkened square was preserved in this condition (Fig. 2C; Bonferroni corrected, one-sided Wilcoxon signed-rank test, $p<0.01)$. However, to obtain a wide-field detailed picture about the underlying activation pattern at the mesoscopic spatial range of "population receptive fields" (Victor et al., 1994; Jancke et al., 1999, 2004b; Dumoulin and Wandell, 2008; Palmer et al., 2012) a denser sampling of neuronal activity than provided by our relatively few (and stimulus centered) electrode recordings would be needed (Jancke, 2000). In the next analysis, we instead exploited the high spatiotemporal resolution of VSD imaging, which enables us to track activity within milliseconds across several millimeters of cortex at submillimeter resolution. The Figure $3 A$, first row, depicts the case where the upper square darkened while the neighboring lower square was brightened (1 experiment, 24 repetitions). Starting from the initial region of the cortical responses representing the upper square (posterior in the images), activity was successively drawn out toward the cortical location representing the brightened square (as indicated by the downward arrows). Thus, we found an asymmetric propagation of activity that was continuously elongated in the form of a cor- tical motion streak that was previously observed with squares moving continuously through space at high velocities (Jancke, 2000; Jancke et al., 2004a) and with squares presented within an apparent motion paradigm (Ahmed et al., 2008; Deco and Roland, 2010). To confirm that our stimulus settings produce perception of apparent motion in humans we performed psychophysical experiments (3 participants, 2 blocks, 40 trials each). We found that motion was perceived in every trial, also for larger square sizes and larger separation distance (see Materials and Methods). Moreover, in all trials the lighter square was identified as moving. To further establish the existence of asymmetric propagation in $\mathrm{V} 1$ we altered the polarity of the luminance changes. Indeed, when the darkening square was located at the lower position and the brightening square in opposition, we found the trajectory reversed (Fig. $3 A$, bottom row). Thus, in both cases a wave front of activity propagated from the cortical sites representing the darkened stimulus toward locations representing the brightened stimulus.

To test whether these findings were independent of background we used a variant of the above paradigm in which the squares counterchanged their luminance on a "split" background (Hock et al., 2002). In this case, the changes in luminance contrast occur for both squares in the same direction, that is, either toward or away from background (Fig. 3B, compare icons at left). Therefore, if oppositely signed changes in luminance contrast were required for the propagation observed with a completely black background, it would have been eliminated with the split background. This, however, was not the case. Our imaging data showed again propagation that was strictly initiated at the cortical locations representing the square that darkened and propagated toward cortical regions representing the square that brightened (Fig. 3B). Figure 3, right column, depicts space-time plots of activity for each condition across a dense sampling of amplitude levels (ie, steps of $1 \%$ in the range between 30 and $70 \%$ of maximum activity). Over all conditions the wave front propagated $3.0 \pm 1.1 \mathrm{~mm} \mathrm{SD}$ (mean across depicted amplitude levels) within $50-70 \mathrm{~ms}$, whereas the back of the wave spread in the opposite 
A
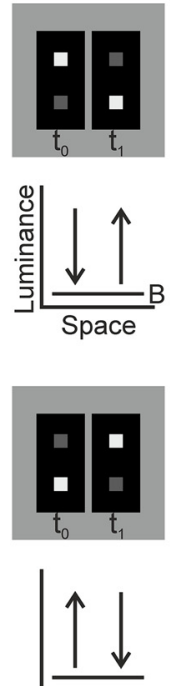

B
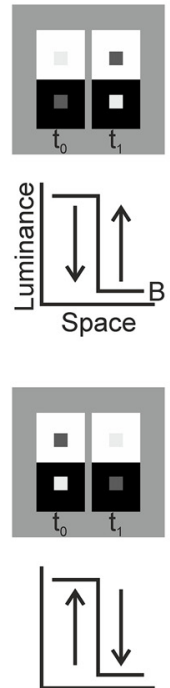

$40 \mathrm{~ms}$
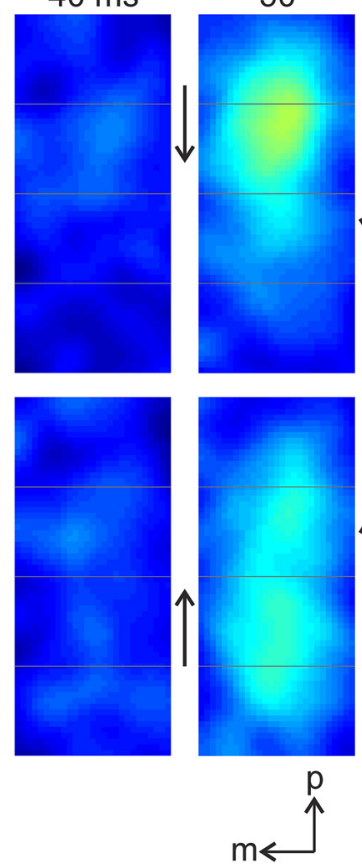

50
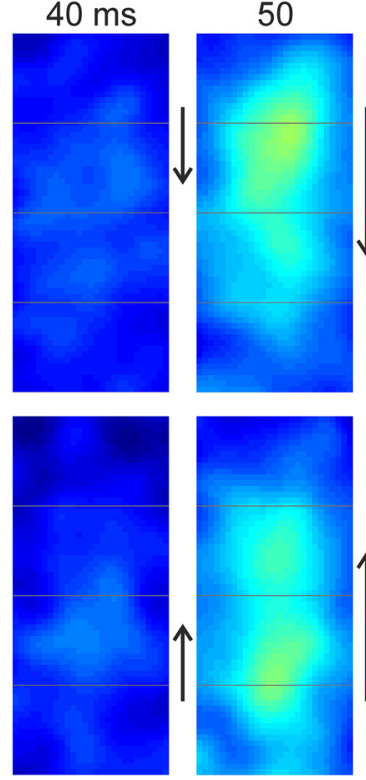

50
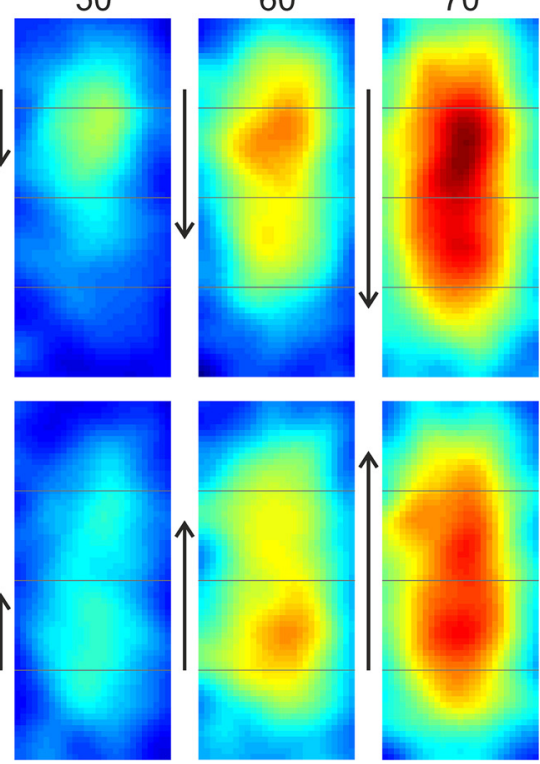

$-0.8$

70

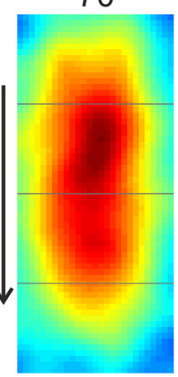

$\Delta \mathrm{F} / \mathrm{F}$
60
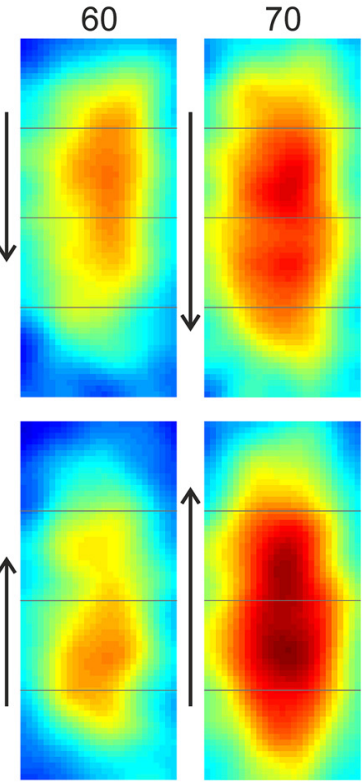

$\Delta \mathrm{F} / \mathrm{F}$

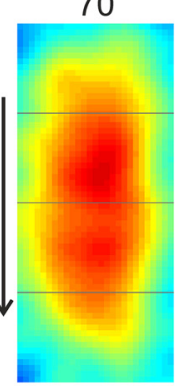

80
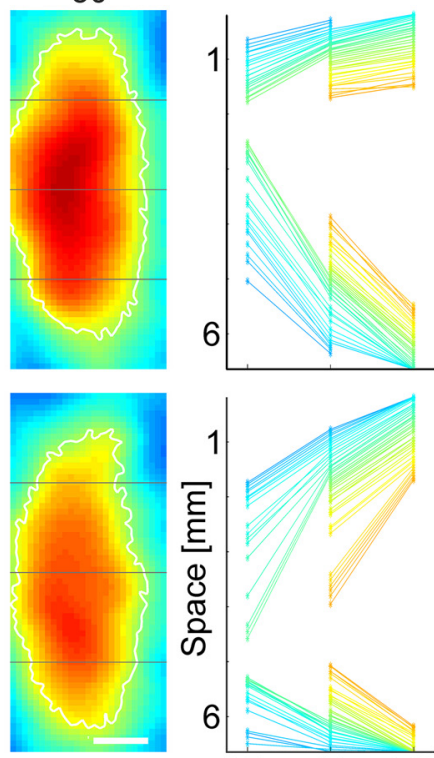

$7.410^{-4}$

80
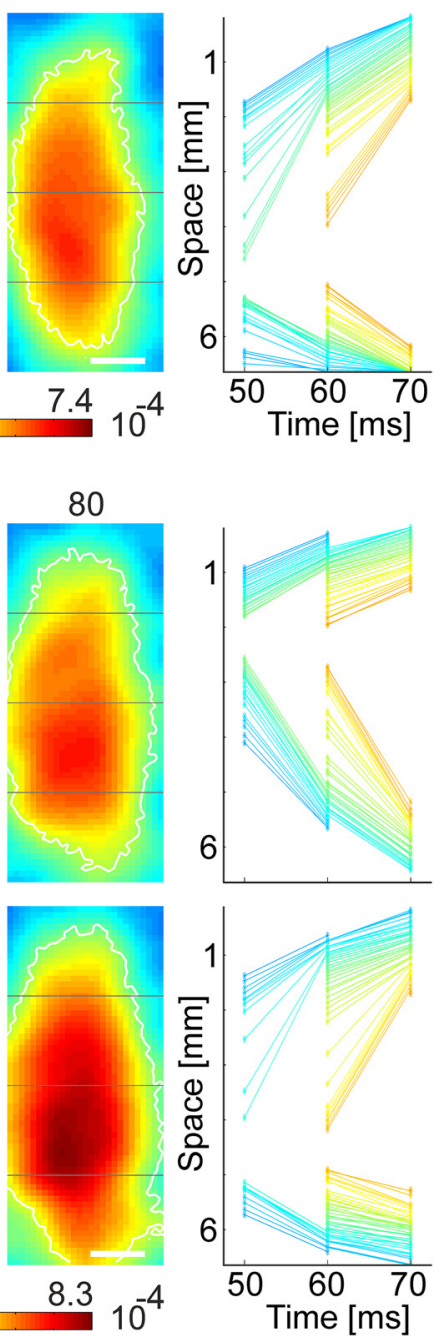

Figure 3. Simultaneous counterchange of luminance initiates asymmetric propagation of activity. $\boldsymbol{A}$, First row, Top square turns dark, whereas bottom square turns bright. Second row, Bottom square turns dark and top square turns bright. $\boldsymbol{B}$, Same experiment and conditions as in $\boldsymbol{A}$, with split background (see text). Color bar indicates activity levels. White contours encircle amplitude levels with Z-score $>3$ (see Materials and Methods). White bar in frame at bottom right $=1 \mathrm{~mm}$; horizontal reference lines are $1.6 \mathrm{~mm}$ apart. Right column, Space-time plots of activity in $1 \%$ steps (30-70\%) of maximum amplitude. Line colors match color scale of image frames. Each line connects locations with same amplitude levels (mean across the central 7 pixels constituting each wave front and back) in anterior and posterior directions.

direction over a distance of $1.2 \pm 0.3 \mathrm{~mm} \mathrm{SD}$. The difference was highly significant $(p<0.001$, two-sided Wilcoxon signed-rank test, pooling over all conditions and both time steps shown), indicating that there was net propagation from the site of the luminance decrement to the site of the luminance increment.

Further confirmation was obtained by either darkening both squares or brightening both squares, again against the split background. As there was no counterchanging luminance for these stimuli a temporal offset of activation between the cortical regions was absent (Fig. 4); activation was close to symmetrical, with no significant difference in spread direction $(p=0.957$, two-sided Wilcoxon signed-rank test, comparing the propagation of all depicted amplitude levels in anterior and posterior directions of both conditions and time steps; Fig. 4A, right column). And in accordance with the previously described results for the brightening and darkening of individual squares, activity was increased for stimulus darkening compared with brightening during the rise time of the responses (Fig. $4 B$, compare green and black traces, mean of 6 different experiments). Together, these results suggest that the cortical propagation depended on asym- 
metric processing of luminance for decrease and increase rather than on the direction of the changes in contrast, supporting psychophysical models of luminance-determined motion that implement greater sensitivity to light decrements than to increments (Backus and Oruc, 2005; Hock et al., 2009).

Note that the asymmetric drawn-out activity occurred within a narrow range of VSD signal amplitudes and could possibly be detected through our imaging technique only at high signal-to-noise ratios and if the gradient of activities between the locations representing $\mathrm{ON}$ and $\mathrm{OFF}$ responses was steep enough. We therefore did not measure responses to stimuli at lower contrasts. In fact, we speculate that the mechanism might be effective only at high-contrast stimulus borders, where the luminance profile allows overcoming noise associated with the detection of spatiotemporal gradients, as suggested in theoretical approaches to human motion detection (Fennema and Thompson, 1979; Marr and Ullman, 1981).

Figure $5 A$ depicts spatial overlays across experiments on the dark background with similar eccentricities $(N=7$, excluding two experiments in which the upper stimulus was either extremely close or most distant to the projection of area centralis, $2.5^{\circ}$ and $17^{\circ}$, respectively). Image frames of the individual experiments were aligned to the center of gravity of the response profiles obtained for stimulation with a single square, separately for its upper and lower locations. When the upper square switched to dark while the lower changed simultaneously to bright, the successive drawing-out of activity in the direction of the cortical region that represented the stimulus increasing in luminance is apparent (Fig. 5A, top). The direction of propagation was reversed when the squares' luminance changes were reversed (Fig. 5A, bottom). Whereas activity representing the back of the wave front spread to a smaller extent and at lower speeds (cf. black and red contours in Fig. 5A), activity at the front of the wave was accelerated $(\sim 54 \%)$ with increasing amplitude (from 0.13 to $0.2 \mathrm{~m} / \mathrm{s} \pm 0.02$ SEM; Fig. $5 B$ ). Overall, this confirms asymmetric propagation of activity across the cortex from regions that represented local stimulus darkening toward regions which represented locations that brightened (Fig. 5, compare stippled/bold arrows and dark/light gray-sketched backgrounds).

Finally, we investigated whether the observed response patterns were a mere result of superimposed activation of the responses to each square alone. We superimposed the responses to luminance changes of the two squares presented in isolation and compared this superposition with responses measured after simultaneous counterchange of luminance of the two squares. Figure 6 depicts spatial averages along the $x$-axis of single $10 \mathrm{~ms}$ image frames for individual experiments. We found that the superposition overestimated the
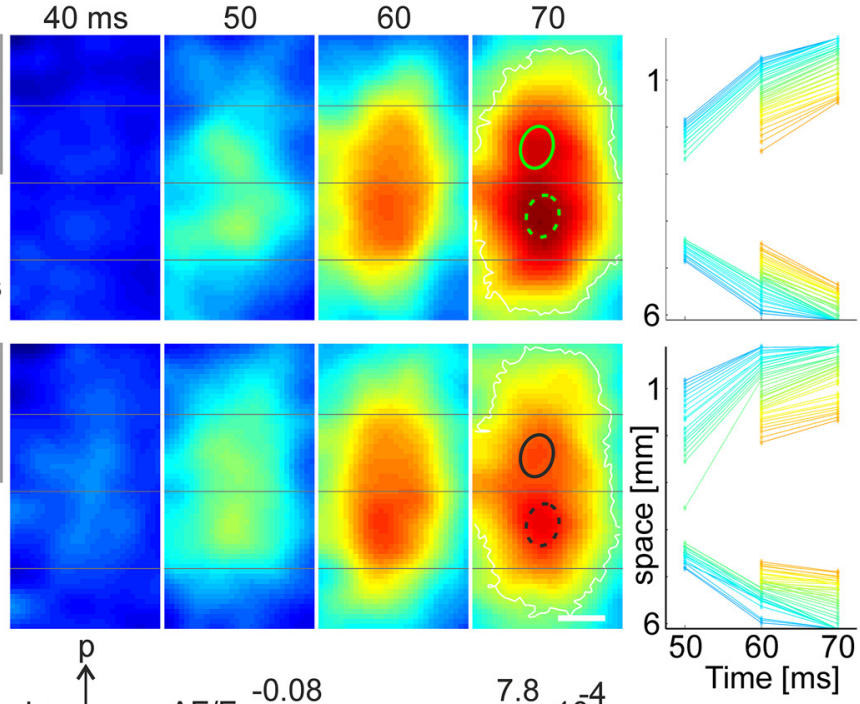

No propagation after counterchange of luminance contrast on split background. $\boldsymbol{A}$, Population activity in response to and bottom squares, concurrent luminance changes lead to counterchanges in contrast at the two locations (see icons at left; $B$ ground luminance). One experiment, 37 trials. White line $=1 \mathrm{~mm}$. p, Posterior; I, lateral. White contours encircle amplitude column, Space-time graphs, same conventions as in Figure 3. B, Responses to brightening (green) and darkening (black) are shown for upper and lower stimulus locations (solid and stippled lines, respectively). The normalized time courses were calculated across thalamic input regions as exemplified in $\boldsymbol{A}$, mean across six different experiments. Error bars $=$ SEM.

amount of activity induced by counterchange. Activity was most strongly suppressed at cortical locations representing the retinotopic position between both squares, particularly during the late phase of the response rise time, with maximum suppression at $110 \mathrm{~ms}$ after stimulus onset (45.4 $\pm 4 \%$ SEM, $p=0.00012$, two-sided Wilcoxon signed-rank test, $N=7$ experiments). These deviations from superposition indicate the presence of nonlinear interactions that may result from mechanisms that are most effective at stimulus borders, but modulate the spatiotemporal dynamics of cortical responses over the entire activated region.

\section{Discussion}

Spatiotemporal asymmetries in the processing of darks and lights affect visual spatial resolution and detection timing (Komban et al., 2014; Kremkow et al., 2014). Here we report that such asymmetries also create motion signals across visual cortex, emerging from an intrinsic temporal asynchrony for the processing of stimulus darkening compared with brightening. 
A

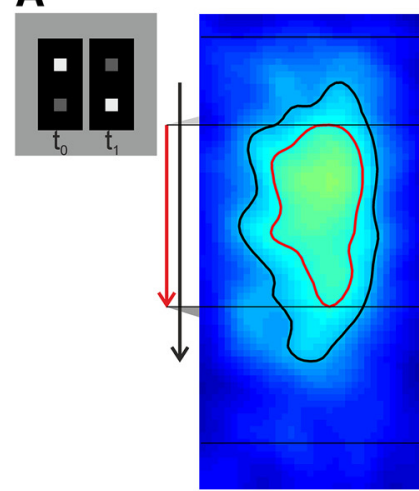

$50 \mathrm{~ms}$
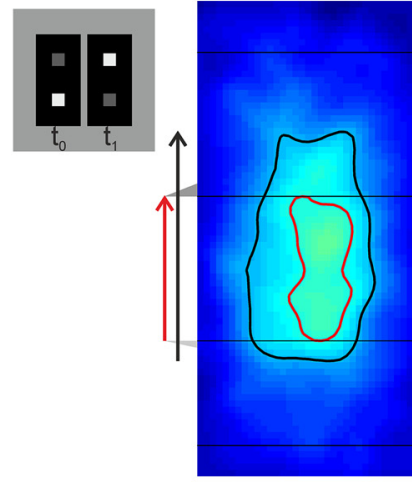

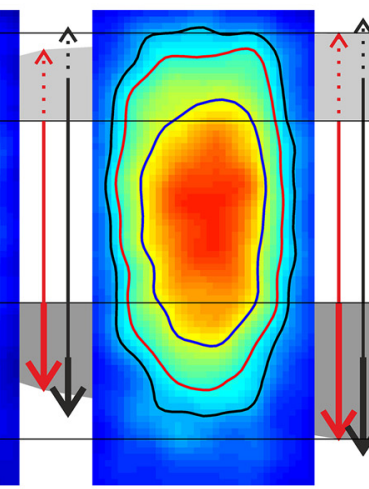

60

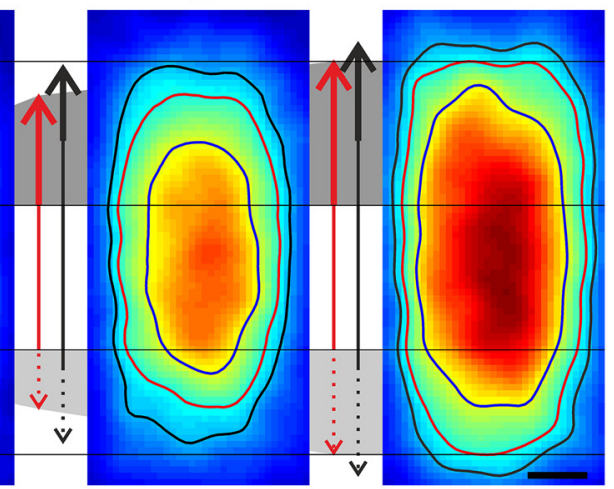

0

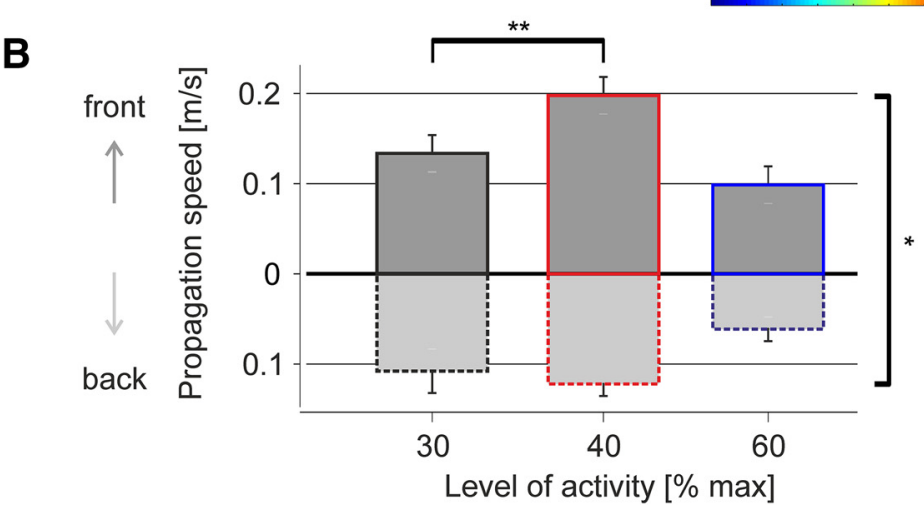

B

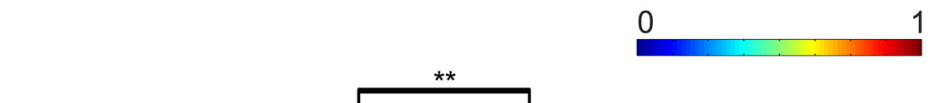

Figure 5. Summary across experiments. $\boldsymbol{A}$, Spatiotemporal overlay of activity patterns of seven different experiments across three time frames, $50-70 \mathrm{~ms}$ from stimulus onset (crosses mark individual penetration sites of electrodes) for two stimulus conditions (see icons and Results): top row demonstrates dominant downward propagation. Bottom row depicts asymmetric propagation in opposite, ie, upward direction. Contour lines mark different levels of activity in percentage of maximum (black = 30 , red $=40$, blue $=60$; each experiment was individually normalized before averaging). Bold arrows mark extension of contours for wave front; stippled arrows delineate spread of activity in the back. $\boldsymbol{B}$, Speed of propagation depended on activity levels and direction (as in $\boldsymbol{A}$; dark gray and bright gray shadings illustrate wave front and back, respectively). Speed was computed for each motion direction and for each individual experiment separately. One-dimensional activity profiles, as shown in Figure 6, were used for calculation. Error bars $=$ SEM. Acceleration of speed of the wave front with increasing amplitude was highly significant ${ }^{* *} p=$ 0.0007 , two-sided Wilcoxon signed-rank test). Such acceleration was not observed in the wave back ( $p=0.094)$, overall characterizing the spatiotemporal differences of the activation patterns ( ${ }^{*} p=0.027$, two-sided Wilcoxon signed-rank test) as asymmetric propagation of activity.

\section{Temporal advance for local stimulus darkening compared with brightening}

Our study builds on previous studies in cat, monkey, and human V1, suggesting that neurons are more strongly driven by darks than lights (Zemon et al., 1988; Jin et al., 2008; Yeh et al., 2009; Xing et al., 2010; Onat et al., 2011; Kremkow et al., 2014; Liu and Yao, 2014). In cat V1, ON/OFF asymmetry in thalamic input distribution coexists with a remarkably limited scatter of the receptive fields of the afferents (Jin et al., 2011b). Hence, it is likely that the coherent temporal advance of population responses that we observed for stimulus darkening reflects uniformly distributed dominant OFF thalamic input. High amplitudes of VSD signals correlated with suprathreshold responses (Petersen et al., 2003; Jancke et al., 2004a; Chen et al., 2012; Nortmann et al., 2015), as was confirmed by our spike recordings. Hence, our results provide further evidence that the temporal advance for the processing of local stimulus darkening, compared with brightening, persists in cortical output (Komban et al., 2014).

\section{Luminance counterchange initiates asymmetric propagation of population activity}

The temporal advance of responses representing the darkened stimulus, together with the earlier response decay for the neighboring brightened stimulus, suggest a simple superposition of activity patterns at both locations to explain propagation. Indeed, the combination of local differences in onsets and offsets of activity was proposed earlier as a basic mechanism for the production of motion waves in cortical networks (Grossberg and Rudd, 1992). However, we found important deviations from a linear overlay of the response patterns. First, the maximum amplitude of activity was subadditive compared with the linear superposition of the responses to each square darkening and brightening alone. This observation is unlikely to be explained by a ceiling effect because responses imaged with stronger stimuli, like full-field gratings, reveal on average twice the amplitude than for local stimulation (Jancke et al., 2004a). Instead, we speculate that local suppression contributes to initiating the propagation of activity. Second, we demonstrated that the speed of the initial spread of activity was accelerated in the wave's motion direction. Because our stimuli produce activity in populations with both strongly overlapping and non-overlapping receptive fields, such acceleration may hint at additional population gain control mechanisms that were recently shown to facilitate the slope of rising activity at high stimulus contrasts (Sit et al., 2009). However, combined suppressive (Hirsch et al., 1998) and facilitatory effects might be mediated primarily by distant-dependent interactions, either within V1, as proposed using a neural field approach (Jancke et al., 1999; Markounikau et al., 2010), or through rapid feedback from higher areas (Bair et al., 2003; Roland et al., 2006). 
Our paradigm in which luminance polarity changes only once and simultaneously at two adjacent locations could, in principle, be compared with conditions in which the stimuli oscillate (Kitano et al., 1995). Indeed, in cat V1 longer multiframe sequences of locally presented contrast-reversing gratings were shown to evoke traveling activity waves, excluding the possibility of a mere iceberg effect for such a paradigm (Benucci et al., 2007). Because of the stimulation protocol, these waves spread symmetrically across the stimulated cortical regions. However, consistent with the wave front's speed estimated here $(\sim 0.2 \mathrm{~m} / \mathrm{s})$, Benucci et al. (2007) found higher speeds of propagation $(0.2-0.5 \mathrm{~m} / \mathrm{s})$ than expected from passive monosynaptic propagation across horizontal axonal fiber connections in vivo (0.1 m/s (Bringuier et al., 1999; Jancke et al., 2004a; Chavane et al., 2011). In fact, simulating responses to contrast reversing square gratings, Sit et al. (2009) proposed that higher propagation speeds arise from population gain control mechanisms. Altogether, we here showed the initiation of propagating activity in response to a single counterchange of luminance, for which accelerated activity expands asymmetrically in one direction, possibly gain modulated and most likely enhanced through further nonlinear lateral interactions (Jancke et al., 2004a; Ahmed et al., 2008).

\section{Retinotopic propagation across visual cortex and the perception of motion}

Counterchange mechanisms comprise pairs of subunits, one responding to decreases and the other to increases in input activation. Any feature could create these activation changes (Seifert and Hock, 2014); eg, a contrast edge or a bright luminance patch moving from one retinal location (activation decreases) to another (activation increases). This flexibility provides redundancy that is crucial for perceiving object motion in natural environments when some object features are hard to discriminate from their background. The flexibility also allows features that contribute to perceiving an object's motion become salient for the perception of the object's shape, and the discrimination of the object from others in the scene. It is therefore tempting to speculate how the observed asymmetric activity wave may be used as a retinotopic spatiotemporal code for motion analysis in brain areas further downstream (Derrington et al., 2004; Burr and Morrone, 2011; Masson and Perrinet, 2012). Under certain conditions, as suggested here for counterchanging luminance at high-contrast borders, asymmetric propagation may contribute directly to the perception of motion (for further possible examples see the famous illusions of Ouchi (1977) and the peripheral drift (Fraser and Wilcox, 1979; Faubert and Herbert, 1999; Backus and Oruc, 2005; Conway et al., 2005), where egomotion of the eye can be tracked across high-contrast local black-to-white gradients in static images). There are several arguments, however, that speak against interpreting the propagating wave observed here as a sig-

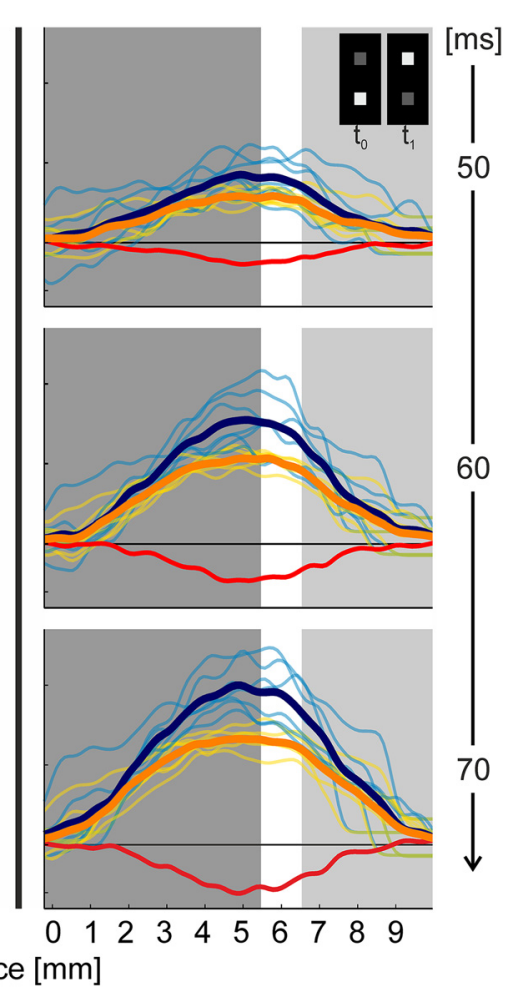

0

0

Space $[\mathrm{mm}]$

Figure 6. Nonlinear interaction. Responses to isolated changes in luminance of the top square were superimposed with re-

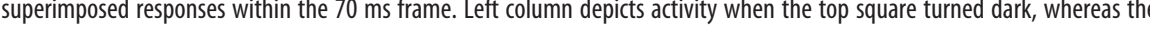
orange and blue mean traces. Suppression increased continuously over time, reaching $34.8 \pm 3.6 \%$ SEM after 70 ms ( $p=$ 0.00012, two-sided Wilcoxon signed-rank test).

nature of an object motion detection mechanism in a strict sense. First, the direction of the wave was independent of the background, that is, activity traveled exclusively from cortical regions representing stimulus darkening toward regions representing the brightened location. Thus, the directional asymmetry characterized here at the joint population level, and previously observed for single cells (Emerson and Gerstein, 1977), is luminancedetermined (Rossi et al., 1996; Mante et al., 2005) and preserves information about contrast polarity. Second, wave generation is most likely confined to high-contrasts, because the gradient between activities representing local darkening and brightening must be sufficiently steep to induce a wave. Third, we did not observe activity pattern that hint at direction-selective responses.

Alternatively, asymmetric propagation of population activity may indirectly influence the brain's analysis of motion (Derrington et al., 2004; Pearson and Westbrook, 2015). Specifically, because activity is rapidly drawn out between two cortical locations, it enables a retinotopic spatial code as it shapes a motion streak across cortex (Jancke et al., 2004a). Using VSD imaging in the awake monkey, such propagation has been shown in V1 after saccades following fixation of a local stimulus (Slovin et al., 2002; Meirovithz et al., 2012). Although the emergence of motion streaks appears to be undesirable per se (ie, mechanisms must exist to perceptually suppress them; Burr, 1980; Kirschfeld and Kammer, 1999; Jancke and Erlhagen, 2010; Ahissar and Arieli, 
2012), motion streaks may be used for brain analysis such as form-from-motion (Braddick, 1974; Jancke, 2000; Lorenceau and Alais, 2001; Jancke et al., 2004a; An et al., 2012, 2014; Mather et al., 2013; Tang et al., 2013; Sun et al., 2014). This is because at higher processing stages information about motion axes can be extracted (Geisler, 1999; Geisler et al., 2001; Burr and Ross, 2002). Interestingly, judgments of stimulus shape by monkeys and humans correlate with the topography of $\mathrm{V} 1$ population activity also for flashed stationary stimuli (Michel et al., 2013). As for the present case, the shape of motion streaks may be read-out, in particular, at retinal locations at which the spatial luminance gradient is sufficiently steep (Marr and Ullman, 1981; Toscani et al., 2013). Such mechanisms could also contribute to stabilizing the retinal image (Murakami and Cavanagh, 1998).

Regardless of whether the propagating activity as reported here may subserve "perceptual knowledge" or cortical analysis of motion (Derrington et al., 2004), any retinotopic encoding of motion further downstream through propagating waves must engage mechanisms that emerge from the topography of early cortical areas, such as V1 (Hedges et al., 2011). Indeed, characterizing human motion detectors in space-time coordinates (Neri and Heeger, 2002) led to the discovery of a previously unknown brief increase in detector amplitude at motion onsets (Neri, 2014). The perceptual relevance of retinotopic encoding of motion trajectories in V1 (Muckli et al., 2005) could furthermore be demonstrated using a "path-guided" apparent motion paradigm in combination with fMRI (Akselrod et al., 2014). The above authors found a curved illusory filling-in of the motion path in V1 that strongly correlated with the observers' perception (Akselrod et al., 2014). Strikingly, in behaving mice V1 activity trajectories correlated with bistable perceptual switches when an apparent motion quartet was used as a stimulus (Zhang et al., 2012). In summary, these results imply that retinotopically propagating activity across V1, as observed in our study, may indeed have implications for the perception of signatures of motion.

\section{References}

Ahissar E, Arieli A (2012) Seeing via miniature eye movements: a dynamic hypothesis for vision. Front Comput Neurosci 6:89. CrossRef Medline

Ahmed B, Hanazawa A, Undeman C, Eriksson D, Valentiniene S, Roland PE (2008) Cortical dynamics subserving visual apparent motion. Cereb Cortex 18:2796-2810. CrossRef Medline

Akselrod M, Herzog MH, Öğmen H (2014) Tracing path-guided apparent motion in human primary visual cortex V1. Sci Rep 4:6063. CrossRef Medline

Albus K (1975) A quantitative study of the projection area of the central and the paracentral visual field in area 17 of the cat: I. The precision of the topography. Exp Brain Res 24:159-179. CrossRef Medline

An X, Gong H, Qian L, Wang X, Pan Y, Zhang X, Yang Y, Wang W (2012) Distinct functional organizations for processing different motion signals in V1, V2, and V4 of macaque. J Neurosci 32:13363-13379. CrossRef Medline

An X, Gong H, McLoughlin N, Yang Y, Wang W (2014) The mechanism for processing random-dot motion at various speeds in early visual cortices. PLoS One 9:e93115. CrossRef Medline

Appelbaum LG, Wade AR, Vildavski VY, Pettet MW, Norcia AM (2006) Cue-invariant networks for figure and background processing in human visual cortex. J Neurosci 26:11695-11708. CrossRef Medline

Appelbaum LG, Ales JM, Norcia AM (2012) The time course of segmentation and cue-selectivity in the human visual cortex. PLoS One 7:e34205. CrossRef Medline

Backus BT, Oruç I (2005) Illusory motion from change over time in the response to contrast and luminance. J Vis 5(11):8 1055-1069. CrossRef Medline

Bair W, Cavanaugh JR, Movshon JA (2003) Time course and time-distance relationships for surround suppression in macaque V1 neurons. J Neurosci 23:7690-7701. Medline
Benucci A, Frazor RA, Carandini M (2007) Standing waves and traveling waves distinguish two circuits in visual cortex. Neuron 55:103-117. CrossRef Medline

Bishop PO, Coombs JS, Henry GH (1971) Responses to visual contours: spatio-temporal aspects of excitation in the receptive fields of simple striate neurones. J Physiol 219:625-657. CrossRef Medline

Blair RC, Karniski W (1993) An alternative method for significance testing of waveform difference potentials. Psychophysiology 30:518-524. CrossRef Medline

Braddick O (1974) A short-range process in apparent motion. Vision Res 14:519-527. CrossRef Medline

Bringuier V, Chavane F, Glaeser L, Frégnac Y (1999) Horizontal propagation of visual activity in the synaptic integration field of area 17 neurons. Science 283:695-699. CrossRef Medline

Burr D (1980) Motion smear. Nature 284:164-165. CrossRef Medline

Burr DC, Morrone MC (2011) Spatiotopic coding and remapping in humans. Philos Trans R Soc Lond B Biol Sci 366:504-515. CrossRef Medline

Burr DC, Ross J (2002) Direct evidence that "speedlines" influence motion mechanisms. J Neurosci 22:8661-8664. Medline

Chavane F, Sharon D, Jancke D, Marre O, Frégnac Y, Grinvald A (2011) Lateral spread of orientation selectivity in V1 is controlled by intracortical cooperativity. Front Syst Neurosci 5:4. CrossRef Medline

Chen Y, Palmer CR, Seidemann E (2012) The relationship between voltagesensitive dye imaging signals and spiking activity of neural populations in primate V1. J Neurophysiol 107:3281-3295. CrossRef Medline

Chichilnisky EJ, Kalmar RS (2002) Functional asymmetries in ON and OFF ganglion cells of primate retina. J Neurosci 22:2737-2747. Medline

Clark DA, Fitzgerald JE, Ales JM, Gohl DM, Silies MA, Norcia AM, Clandinin TR (2014) Flies and humans share a motion estimation strategy that exploits natural scene statistics. Nat Neurosci 17:296-303. CrossRef Medline

Conway BR, Kitaoka A, Yazdanbakhsh A, Pack CC, Livingstone MS (2005) Neural basis for a powerful static motion illusion. J Neurosci 25:5651-5656. CrossRef Medline

Cooper EA, Norcia AM (2015) Predicting cortical dark/bright asymmetries from natural image statistics and early visual transforms. PLoS Comput Biol 11:e1004268. CrossRef Medline

Creutzfeldt OD, Garey LJ, Kuroda R, Wolff JR (1977) The distribution of degenerating axons after small lesions in the intact and isolated visual cortex of the cat. Exp Brain Res 27:419-440. Medline

Deco G, Roland P (2010) The role of multi-area interactions for the computation of apparent motion. Neuroimage 51:1018-1026. CrossRef Medline

Derrington AM, Allen HA, Delicato LS (2004) Visual mechanisms of motion analysis and motion perception. Annu Rev Psychol 55:181-205. CrossRef Medline

Dinse HR, Jancke D (2001) Time-variant processing in V1: from microscopic (single cell) to mesoscopic (population) levels. Trends Neurosci 24:203-205. CrossRef Medline

Dumoulin SO, Wandell BA (2008) Population receptive field estimates in human visual cortex. Neuroimage 39:647-660. CrossRef Medline

Emerson RC, Gerstein GL (1977) Simple striate neurons in the cat: II. Mechanisms underlying directional asymmetry and directional selectivity. J Neurophysiol 40:136-155. Medline

Faubert J, Herbert AM (1999) The peripheral drift illusion: a motion illusion in the visual periphery. Perception 28:617-621. CrossRef Medline

Fennema CL, Thompson WB (1979) Velocity determination in scenes containing several moving objects. Comput Graph Image Process 9:301-315. CrossRef

Ferster D (1986) Orientation selectivity of synaptic potentials in neurons of cat primary visual cortex. J Neurosci 6:1284-1301. Medline

Fisken RA, Garey LJ, Powell TP (1975) The intrinsic, association and commissural connections of area 17 on the visual cortex. Philos Trans R Soc Lond B Biol Sci 272:487-536. CrossRef Medline

Fraser A, Wilcox KJ (1979) Perception of illusory movement. Nature 281: 565-566. CrossRef Medline

Freeman WJ, Barrie JM (2000) Analysis of spatial patterns of phase in neocortical gamma EEGs in rabbit. J Neurophysiol 84:1266-1278. Medline

Geisler WS (1999) Motion streaks provide a spatial code for motion direction. Nature 400:65-69. CrossRef Medline

Geisler WS (2008) Visual perception and the statistical properties of natural scenes. Annu Rev Psychol 59:167-192. CrossRef Medline 
Geisler WS, Albrecht DG, Crane AM, Stern L (2001) Motion direction signals in the primary visual cortex of cat and monkey. Vis Neurosci 18: 501-516. CrossRef Medline

Gilbert CD, Wiesel TN (1979) Morphology and intracortical projections of functionally characterised neurones in the cat visual cortex. Nature 280: 120-125. CrossRef Medline

Grinvald A, Hildesheim R (2004) VSDI: a new era in functional imaging of cortical dynamics. Nat Rev Neurosci 5:874-885. CrossRef Medline

Grinvald A, Lieke EE, Frostig RD, Hildesheim R (1994) Cortical pointspread function and long-range lateral interactions revealed by real-time optical imaging of macaque monkey primary visual cortex. J Neurosci 14:2545-2568. Medline

Grossberg S, Rudd ME (1992) Cortical dynamics of visual motion perception: short-range and long-range apparent motion. Psychol Rev 99: 78-121. CrossRef Medline

Hedges JH, Gartshteyn Y, Kohn A, Rust NC, Shadlen MN, Newsome WT, Movshon JA (2011) Dissociation of neuronal and psychophysical responses to local and global motion. Curr Biol 21:2023-2028. CrossRef Medline

Hirsch JA, Alonso JM, Reid RC, Martinez LM (1998) Synaptic integration in striate cortical simple cells. J Neurosci 18:9517-9528. Medline

Hock HS, Gilroy LA, Harnett G (2002) Counter-changing luminance: a non-Fourier, non-attentional basis for the perception of single-element apparent motion. J Exp Psychol Hum Percept Perform 28:93-112. CrossRef

Hock HS, Schöner G, Gilroy L (2009) A counterchange mechanism for the perception of motion. Acta Psychol (Amst) 132:1-21. CrossRef Medline

Jancke D (2000) Orientation formed by a spot's trajectory: a twodimensional population approach in primary visual cortex. J Neurosci 20:RC86. Medline

Jancke D, Erlhagen W (2010) Bridging the gap: a model of common neural mechanisms underlying the Fröhlich effect, the flash-lag effect, and the representational momentum effect. In: Space and time in perception and action (Nijhawan R, Khurana B, eds), Cambridge, UK: Cambridge UP.

Jancke D, Erlhagen W, Dinse HR, Akhavan AC, Giese M, Steinhage A, Schöner G (1999) Parametric population representation of retinal location: neuronal interaction dynamics in cat primary visual cortex. J Neurosci 19:9016-9028. Medline

Jancke D, Chavane F, Naaman S, Grinvald A (2004a) Imaging cortical correlates of illusion in early visual cortex. Nature 428:423-426. CrossRef Medline

Jancke D, Erlhagen W, Schöner G, Dinse HR (2004b) Shorter latencies for motion trajectories than for flashes in population responses of cat primary visual cortex. J Physiol 556:971-982. CrossRef Medline

Jin J, Wang Y, Lashgari R, Swadlow HA, Alonso JM (2011a) Faster thalamocortical processing for dark than light visual targets. J Neurosci 31:17471-17479. CrossRef Medline

Jin J, Wang Y, Swadlow HA, Alonso JM (2011b) Population receptive fields of ON and OFF thalamic inputs to an orientation column in visual cortex. Nat Neurosci 14:232-238. CrossRef Medline

Jin JZ, Weng C, Yeh CI, Gordon JA, Ruthazer ES, Stryker MP, Swadlow HA, Alonso JM (2008) On and off domains of geniculate afferents in cat primary visual cortex. Nat Neurosci 11:88-94. CrossRef Medline

Kirschfeld K, Kammer T (1999) The Frohlich effect: a consequence of the interaction of visual focal attention and metacontrast. Vision Res 39: 3702-3709. CrossRef Medline

Kitano M, Kasamatsu T, Norcia AM, Sutter EE (1995) Spatially distributed responses induced by contrast reversal in cat visual cortex. Exp Brain Res 104:297-309. Medline

Komban SJ, Kremkow J, Jin J, Wang Y, Lashgari R, Li X, Zaidi Q, Alonso JM (2014) Neuronal and perceptual differences in the temporal processing of darks and lights. Neuron 82:224-234. CrossRef Medline

Kremkow J, Jin J, Komban SJ, Wang Y, Lashgari R, Li X, Jansen M, Zaidi Q, Alonso JM (2014) Neuronal nonlinearity explains greater visual spatial resolution for darks than lights. Proc Natl Acad Sci U S A 111:3170-3175. CrossRef Medline

Liu K, Yao H (2014) Contrast-dependent OFF-dominance in cat primary visual cortex facilitates discrimination of stimuli with natural contrast statistics. Eur J Neurosci 39:2060-2070. CrossRef Medline

Lorenceau J, Alais D (2001) Form constraints in motion binding. Nat Neurosci 4:745-751. CrossRef Medline

Mante V, Frazor RA, Bonin V, Geisler WS, Carandini M (2005) Indepen- dence of luminance and contrast in natural scenes and in the early visual system. Nat Neurosci 8:1690-1697. CrossRef Medline

Markounikau V, Igel C, Grinvald A, Jancke D (2010) A dynamic neural field model of mesoscopic cortical activity captured with voltage-sensitive dye imaging. PLoS Comput Biol 6:e1000919. CrossRef Medline

Marr D, Ullman S (1981) Directional selectivity and its use in early visual processing. Proc R Soc Lond B Biol Sci 211:151-180. CrossRef Medline

Masson GS, Perrinet LU (2012) The behavioral receptive field underlying motion integration for primate tracking eye movements. Neurosci Biobehav Rev 36:1-25. CrossRef Medline

Mather G, Pavan A, Bellacosa Marotti R, Campana G, Casco C (2013) Interactions between motion and form processing in the human visual system. Front Comput Neurosci 7:65. CrossRef Medline

McCamy MB, Otero-Millan J, Di Stasi LL, Macknik SL, Martinez-Conde S (2014) Highly informative natural scene regions increase microsaccade production during visual scanning. J Neurosci 34:2956-2966. CrossRef Medline

Meirovithz E, Ayzenshtat I, Werner-Reiss U, Shamir I, Slovin H (2012) Spatiotemporal effects of microsaccades on population activity in the visual cortex of monkeys during fixation. Cereb Cortex 22:294-307. CrossRef Medline

Michel MM, Chen Y, Geisler WS, Seidemann E (2013) An illusion predicted by $\mathrm{V} 1$ population activity implicates cortical topography in shape perception. Nat Neurosci 16:1477-1483. CrossRef Medline

Muckli L, Kohler A, Kriegeskorte N, Singer W (2005) Primary visual cortex activity along the apparent-motion trace reflects illusory perception. PLoS Biol 3:e265. CrossRef Medline

Murakami I, Cavanagh P (1998) A jitter after-effect reveals motion-based stabilization of vision. Nature 395:798-801. CrossRef Medline

Nelson SB (1991) Temporal interactions in the cat visual system: I. Orientationselective suppression in the visual cortex. J Neurosci 11:344-356. Medline

Neri P (2014) Dynamic engagement of human motion detectors across space-time coordinates. J Neurosci 34:8449-8461. CrossRef Medline

Neri P, Heeger DJ (2002) Spatiotemporal mechanisms for detecting and identifying image features in human vision. Nat Neurosci 5:812-816. CrossRef Medline

Nortmann N, Rekauzke S, Onat S, König P, Jancke D (2015) Primary visual cortex represents the difference between past and present. Cereb Cortex 25:1427-1440. CrossRef Medline

Onat S, Nortmann N, Rekauzke S, König P, Jancke D (2011) Independent encoding of grating motion across stationary feature maps in primary visual cortex visualized with voltage-sensitive dye imaging. Neuroimage 55:1763-1770. CrossRef Medline

Onat S, Jancke D, König P (2013) Cortical long-range interactions embed statistical knowledge of natural sensory input: a voltage-sensitive dye imaging study. F1000Res 2:51. CrossRef Medline

Ouchi H (1977) Japanese and geometrical art. New York: Dover.

Palagina G, Eysel UT, Jancke D (2009) Strengthening of lateral activation in adult rat visual cortex after retinal lesions captured with voltage-sensitive dye imaging in vivo. Proc Natl Acad Sci U S A 106:8743-8747. CrossRef Medline

Palmer CR, Chen Y, Seidemann E (2012) Uniform spatial spread of population activity in primate parafoveal V1. J Neurophysiol 107:1857-1867. CrossRef Medline

Pearson J, Westbrook F (2015) Phantom perception: voluntary and involuntary nonretinal vision. Trends Cogn Sci 19:278-284. CrossRef Medline

Petersen CC, Grinvald A, Sakmann B (2003) Spatiotemporal dynamics of sensory responses in layer $2 / 3$ of rat barrel cortex measured in vivo by voltage-sensitive dye imaging combined with whole-cell voltage recordings and neuron reconstructions. J Neurosci 23:1298-1309. Medline

Polack PO, Contreras D (2012) Long-range parallel processing and local recurrent activity in the visual cortex of the mouse. J Neurosci 32:1112011131. CrossRef Medline

Ratliff CP, Borghuis BG, Kao YH, Sterling P, Balasubramanian V (2010) Retina is structured to process an excess of darkness in natural scenes. Proc Natl Acad Sci U S A 107:17368-17373. CrossRef Medline

Roland PE, Hanazawa A, Undeman C, Eriksson D, Tompa T, Nakamura H, Valentiniene S, Ahmed B (2006) Cortical feedback depolarization waves: a mechanism of top-down influence on early visual areas. Proc Natl Acad Sci U S A 103:12586-12591. CrossRef Medline

Rossi AF, Rittenhouse CD, Paradiso MA (1996) The representation of brightness in primary visual cortex. Science 273:1104-1107. CrossRef Medline 
Ruderman DL, Bialek W (1994) Statistics of natural images: scaling in the woods. Phys Rev Lett 73:814-817. CrossRef Medline

Seifert M, Hock HS (2014) The independent detection of motion energy and counterchange: flexibility in motion detection. Vision Res 98:61-71. CrossRef Medline

Sharon D, Jancke D, Chavane F, Na'aman S, Grinvald A (2007) Cortical response field dynamics in cat visual cortex. Cereb Cortex 17:2866-2877. CrossRef Medline

Sit YF, Chen Y, Geisler WS, Miikkulainen R, Seidemann E (2009) Complex dynamics of $\mathrm{V} 1$ population responses explained by a simple gain-control model. Neuron 64:943-956. CrossRef Medline

Slovin H, Arieli A, Hildesheim R, Grinvald A (2002) Long-term voltagesensitive dye imaging reveals cortical dynamics in behaving monkeys. J Neurophysiol 88:3421-3438. CrossRef Medline

Sun P, Chubb C, Sperling G (2014) A moving-barber-pole illusion. J Vis 14(5):1 1-27. CrossRef Medline

Tang MF, Dickinson JE, Visser TA, Edwards M, Badcock DR (2013) The shape of motion perception: global pooling of transformational apparent motion. J Vis 13(13):20 1-20. CrossRef Medline

Toscani M, Valsecchi M, Gegenfurtner KR (2013) Optimal sampling of visual information for lightness judgments. Proc Natl Acad Sci U S A 110: 11163-11168. CrossRef Medline
Victor JD, Purpura K, Katz E, Mao B (1994) Population encoding of spatial frequency, orientation, and color in macaque V1. J Neurophysiol 72: 2151-2166. Medline

Xing D, Yeh CI, Shapley RM (2010) Generation of black-dominant responses in V1 cortex. J Neurosci 30:13504-13512. CrossRef Medline

Yeh CI, Xing D, Shapley RM (2009) "Black" responses dominate macaque primary visual cortex v1. J Neurosci 29:11753-11760. CrossRef Medline

Yin J, Gong H, An X, Chen Z, Lu Y, Andolina IM, McLoughlin N, Wang W (2015) Breaking cover: neural responses to slow and fast camouflagebreaking motion. Proc Biol Sci 282:20151182. CrossRef Medline

Zaghloul KA, Boahen K, Demb JB (2003) Different circuits for ON and OFF retinal ganglion cells cause different contrast sensitivities. J Neurosci 23: 2645-2654. Medline

Zemon V, Gordon J, Welch J (1988) Asymmetries in ON and OFF visual pathways of humans revealed using contrast-evoked cortical potentials. Vis Neurosci 1:145-150. CrossRef Medline

Zhang QF, Wen Y, Zhang D, She L, Wu JY, Dan Y, Poo MM (2012) Priming with real motion biases visual cortical response to bistable apparent motion. Proc Natl Acad Sci U S A 109:20691-20696. CrossRef Medline

Zurawel G, Ayzenshtat I, Zweig S, Shapley R, Slovin H (2014) A contrast and surface code explains complex responses to black and white stimuli in V1. J Neurosci 34:14388-14402. CrossRef Medline 